\title{
Potencialidade da Casca de Caranguejo na Redução da Incidência de Fusariose e na Promoção do Crescimento de Mudas de Pimenteira-do-Reino
}

\author{
Ruth L. Benchimol ${ }^{1}$, John C. Sutton ${ }^{2} \&$ Moacyr B. Dias-Filho ${ }^{1}$ \\ ${ }^{1}$ Embrapa Amazônia Oriental, Cx. Postal 48, CEP 66017-970, Belém, PA, \\ e-mails: rlinda@cpatu.embrapa.br; moacyr@cpatu.embrapa.br; ${ }^{2}$ University of Guelph, Ontario Agricultural College, \\ N1G 2W1, Guelph, Ontario, Canada, e-mail: jcsutton@uoguelph.ca
}

(Aceito para publicação em 05/12/2005)

Autor para correspondência: Ruth Linda Benchimol

BENCHIMOL, R.L., SUTTON, J. C. \& DIAS-FILHO, M. B. Potencialidade da casca de caranguejo na redução da incidência de fusariose e na promoção do crescimento de mudas de pimenteira-do-reino. Fitopatologia Brasileira 31:180-184. 2006.

\begin{abstract}
RESUMO
A casca de caranguejo-do-mangue (Ucides cordatus) foi testada como aditivo ao solo para reduzir a incidência de fusariose (Fusarium solani f.sp. piperis) e para promover o crescimento de mudas de pimenteira-do-reino (Piper nigrum). A pré-incubação da casca de caranguejo no solo (1,0\% m/m; 15 dias) antes do transplantio aumentou em $20 \%$ a sobrevivência da pimenteira-do-reino, cultivada em solo infestado com Fusarium solani f. sp. piperis, durante 90 dias. A produção de massa seca das plantas aumentou na presença de casca de caranguejo, independente da concentração e do tempo de incubação no solo. As plantas alocaram biomassa preferencialmente para a parte aérea, na presença de casca de caranguejo. A taxa de fotossíntese líquida das plantas tendeu a aumentar ou permaneceu inalterada na presença de casca de caranguejo. Conclui-se que a casca de caranguejo tem potencial para auxiliar na redução da incidência de fusariose e no desenvolvimento de mudas de pimenteira-do-reino. cordatus.

Palavras-chave adicionais: Caranguejo-do-mangue, Fusarium solani f. sp. piperis, Piper nigrum, Ucides

ABSTRACT

Potential of crab shell for reducing incidence of fusariosis and promoting growth of black pepper transplants

Crab shell of the mangrove crab (Ucides cordatus) was tested as a soil amendment to reduce fusariosis and promote growth of black pepper (Piper nigrum) transplants. Soil infested with Fusarium solani f. sp. piperis was amended or not amended with ground crab shell $(1,0 \% \mathrm{~m} / \mathrm{m}) 15$ days before pepper seedlings were transplanted into the soil. The crab shell amendment increased plant survival by $20 \%$ at 90 days after transplanting. The amendment increased the production of plant dry mass when applied at various concentrations and times before transplanting. The increased biomass of plants grown in amended soil was allocated preferentially to the aerial plant parts, mainly the leaves. Net photosynthesis increased or was unchanged in plants grown in the presence of 0.5 and $1.0 \%(\mathrm{~m} / \mathrm{m})$ of crab shell. We conclude that ground crab shell has potential to reduce incidence of fusariosis and to promote the growth of black pepper.
\end{abstract}

Additional keywords: Fusarium solani f. sp. piperis, Mangrove crab, Piper nigrum, Ucides cordatus.

\section{INTRODUÇÃO}

A fusariose, provocada por Fusarium solani f. sp. piperis F.C Albuq., é uma das doenças mais prejudiciais à cultura da pimenta-do-reino (Piper nigrum L.) na Amazônia, tendo acarretado perdas econômicas inestimáveis aos produtores dessa especiaria, desde a sua detecção no estado do Pará no final da década de 50 (Albuquerque, 1961; CENDETECA, 1995; Duarte \& Albuquerque, 1999; Pará, 2004).

Dentre as estratégias de controle da fusariose, a aplicação de fungicidas tem sido tradicionalmente recomendada. Porém, a eficiência biológica e econômica do controle químico é limitada, podendo causar, ainda, prejuízos ao ambiente. A aplicação de materiais orgânicos no solo pode ser considerada como uma alternativa de controle dessa doença. Entre esses materiais, encontrase a casca de caranguejo, que apresenta quitina em sua composição (Ehteshamul-Haque, 1997), além de macro- e micronutrientes (Benchimol, 2002). A quitina é um polissacarídeo degradável de ocorrência comum na natureza. É o maior componente estrutural da parede celular da maioria dos fungos, compondo 39\% da parede celular daqueles pertencentes ao gênero Fusarium (Griffin, 1993). A adição de quitina ao solo leva ao aumento da população de microrganismos quitinolíticos e à supressão de fungos fitopatogênicos e fitonematóides presentes no solo (Sneh et al., 1971; Mian et al., 1982; Godoy et al., 1983; RodríguezKábana et al., 1983; Boller, 1986; Rafferty et al., 2003) estando essa substância associada ao aumento da sanidade das raízes e do estande de plantas no campo, quando 
Potencialidade da casca de carangueijo na redução da incidência...

adicionada em mistura com outros compostos orgânicos (Lin et al., 1969).

A quitina, tanto na sua forma pura, de seus derivados, ou como parte da composição de substâncias orgânicas, como a casca de caranguejo, ou ainda como componente de compostos orgânicos, tem sido testada na agricultura para diversos fins, entre os quais a promoção do crescimento de plantas (Ali et al., 1998), o controle de nematóides fitoparasitas (Mian et al., 1982; Kahn et al., 2002) e o controle de fitopatógenos (Tu et al., 1992).

No Estado do Pará, na região da Amazônia oriental brasileira, o caranguejo do mangue (Ucides cordatus L.), encontrado em abundância nos manguezais da região, é um dos pratos típicos mais apreciados pela população. O alto consumo desse crustáceo tem gerado subprodutos da extração de carne, principalmente a carapaça, ou casquinho, que na maioria das vezes é subaproveitada ou descartada, desconsiderando o potencial econômico e o benefício social que poderiam advir da utilização desse resíduo.

Embora seja conhecido o fato de que alguns agricultores, principalmente na região de Tomé-Açú, PA, vêm utilizando a casca de caranguejo como componente de compostos para a produção de hortaliças, com relatos positivos no que se refere às condições fitossanitárias e de desenvolvimento das plantas, não há registros científicos do possível efeito da utilização da casca de caranguejo no controle de doenças e no desenvolvimento de plantas na Amazônia. Há evidências, porém, de que a adição de casca de caranguejo, ou de seus componentes e derivados, ao solo pode controlar doenças, estimular o desenvolvimento de plantas e promover incremento na microbiota do solo. A incidência de podridão de raiz em feijão (Phaseolus vulgaris L.), causada por Fusarium solani f. sp. phaseoli (Burkh.) W.C. Snyder \& H.N. Hansen, e de murcha em nabo (Raphanus sativus L.), causada por Fusarium oxysporum f.sp. raphani J.B. Kendrick \& W.C. Snyder foram reduzidas pela adição de quitina em solos artificialmente infestados pelos patógenos (Mitchell \& Alexander, 1961). A adição de casca de caranguejo ao solo, imediatamente antes da semeadura de soja (Glycine max Merr.), provocou aumento na produção e peso de sementes, semelhante ao obtido no tratamento com fertilizante NPK, utilizado convencionalmente na cultura (Ali et al., 1998). O desenvolvimento satisfatório de plântulas de repolho (Brassica oleraceae L.) e a supressão do tombamento provocado por Rhizoctonia solani J.G. Kühn foram obtidos com a utilização de substrato composto de casca de caranguejo e outros materiais orgânicos (Huang \& Huang, 2000).

O objetivo do trabalho foi testar, em condições semicontroladas, o efeito da casca de caranguejo na redução da incidência de fusariose e na melhoria do desenvolvimento de mudas de pimenteira-do-reino.

\section{MATERIAL E MÉTODOS}

A pesquisa foi conduzida no Campo Experimental

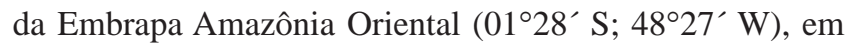
Belém, PA, em condições de ambiente semi-controlado, com $50 \%$ de sombreamento e temperatura e umidade relativa do ar na faixa de $25-35{ }^{\circ} \mathrm{C}$ e $80-95 \%$, respectivamente.

A casca de caranguejo utilizada nos experimentos foi obtida por meio de coleta dos resíduos da extração da carne desse crustáceo, principalmente as carapaças, nos municípios de Capanema, Bragança e Belém, estado do Pará. Para utilização no experimento, o material foi submetido à lavagem com $\mathrm{NaClO} 0,2 \%$ por cerca de $1 \mathrm{~h}$, seguida de água corrente. Após secagem ao sol, por cerca de três dias, o material foi triturado e moído até a forma de pó (partículas $<2 \mathrm{~mm}$ ), apresentando a seguinte composição: $\mathrm{N}=10,6 ; \mathrm{P}=10,6 ; \mathrm{K}=0,4 ; \mathrm{Ca}=437,1 ; \mathrm{Mg}=8,7$ e $\mathrm{S}=0,6\left(\mathrm{~g} \mathrm{~kg}^{-1}\right)$ e $\mathrm{B}=2,6 ; \mathrm{Cu}=1,2 ; \mathrm{Mn}=24,4 ; \mathrm{Zn}=7,8$ e $\mathrm{Fe}=77,9\left(\mathrm{mg} \mathrm{kg}^{-1}\right)$; umidade $=8,16 \%$; cinza $=71,82 \%$ e proteína $=6,36 \%$.

A casca de caranguejo moída foi misturada a solo de matanão(M) ou previamenteautoclavado (A), nas proporções de 0,5 e $1,0 \%(\mathrm{~m} / \mathrm{m})$ e incubada por 15 ou 30 dias. O inóculo do patógeno foi multiplicado em meio de BS (batata 200 g; sacarose $20 \mathrm{~g}$ ), sob condições de temperatura controlada (27 $\left.\pm 1{ }^{\circ} \mathrm{C}\right)$, agitação mecânica rotativa (100 rpm) e luz fluorescente em regime alternado ( $12 \mathrm{~h}$ claro/ $12 \mathrm{~h}$ escuro), durante oito dias. A cultura líquida do patógeno (micélio, macro e microconídios) foi filtrada em gaze esterilizada e a suspensão assim obtida foi ajustada para a concentração de $10^{6}$ macroconídios $\mathrm{mL}^{-1}$ (Tuite, 1969), uma vez que estes são capazes de causar infecção quando adicionados ao solo nessa concentração. O inóculo foi adicionado ao solo (20 $\mathrm{mL} /$ vaso de $500 \mathrm{~mL}$ ) sete dias após o transplantio de plantas da cv. Guajarina, com oito meses. O fertilizante Kiowa (88-8-1 NPK-Mg) foi regado em cada vaso (20 mL/vaso; 10 g/20 L água), sete dias após a instalação do experimento, com periodicidade bimensal até o final do experimento.

$\mathrm{O}$ delineamento experimental foi inteiramente casualizado, em arranjo fatorial 3x3, com cinco repetições. O experimento teve a duração de 150 dias. A sobrevivência das plantas foi avaliada durante 90 dias, pela ausência (100) ou presença (0) de sintomas de fusariose no coleto da planta, semanalmente, iniciando-se 15 dias após a instalação do experimento. O carbono da biomassa microbiana do solo (BMS) foi avaliado aos 45 dias da instalação do experimento, pelo método da fumigação-extração (Vance et al., 1987; Tate et al., 1988). A produção de massa seca foi avaliada ao final do experimento, por meio da determinação da massa seca de folhas, hastes e raízes de cada planta, em estufa de circulação forçada, a $75{ }^{\circ} \mathrm{C}$, por $72 \mathrm{~h}$. Esses dados foram utilizados para avaliar a alocação de biomassa das plantas. O comportamento fotossintético das plantas foi avaliado ao final do experimento, utilizando-se a folha mais nova, intacta e completamente desenvolvida de cada planta. As medições foram feitas no horário de 9 às 11 h, utilizando um sistema de fotossíntese portátil (Modelo LI-6400, LI-COR Inc., Lincoln, NE, EUA). O programa estatístico Statistica for Windows 5.5 (Statistica for Windows, 1995) foi utilizado para análise dos dados. 


\section{RESULTADOS E DISCUSSÃO}

A análise dos dados mostrou que a casca de caranguejo a 1,0\%, pré-incubada por 15 dias em solo de mata não autoclavado, e por 30 dias em solo de mata autoclavado, reduziu a mortalidade das mudas de pimenteira-do-reino por F. solani f. sp. piperis em $20 \%\left(\mathrm{~F}_{2,144}=25,65 ; \mathrm{p}<0,001\right)$, em relação as mudas cultivadas em solo sem casca. É possível supor que esse aumento na sobrevivência das plantas foi, provavelmente, provocado pela atuação de microrganismos degradadores de quitina contra $F$. solani f. sp. piperis, o qual contém quitina em sua parede celular (Griffin, 1993). Esses microrganismos poderiam estar presentes no solo de mata não autoclavado quando da adição da casca de caranguejo, exigindo um menor tempo de pré-incubação dessa substância para estimular sua multiplicação. Segundo Bettiol \& Ghini (2004), a diminuição da incidência de podridão de raízes causada por Fusarium spp. em diferentes culturas pela adição de casca de camarão moída (fonte de quitina) ao solo é atribuída ao estímulo do desenvolvimento de microrganismos antagônicos ao patógeno.

A biomassa microbiana do solo tendeu a ser maior em solo de mata não autoclavado do que em solo de mata autoclavado, notadamente quando a casca de caranguejo, a 1,0\%, foi pré-incubada (Figura 1). O aumento nas comunidades de fungos e bactérias em solo de mata autoclavado adicionado de quitina tem sido atribuído ao aumento do suprimento de $\mathrm{C}$ e $\mathrm{N}$, advindo da adição dessa substância (Brown et al.,1995; Saratchandra et al., 1996; Hallman et al.,1998). As modificações biológicas provocadas no solo pela adição de quitina são relatadas em vários estudos com o gênero Fusarium (Adachi et al., 1987; Mitchell \& Alexander, 1962). Essas mudanças biológicas levam a crer que, no presente estudo, os microrganismos degradadores da quitina, oriundos da casca de caranguejo, foram os principais responsáveis pelo prolongamento da sobrevivência das plantas. Embora não tenha sido possível determinar o tipo de microbiota presente no solo, o fato da biomassa microbiana do solo ter sido maior na presença da casca de caranguejo, sugere a existência dessa microbiota específica.

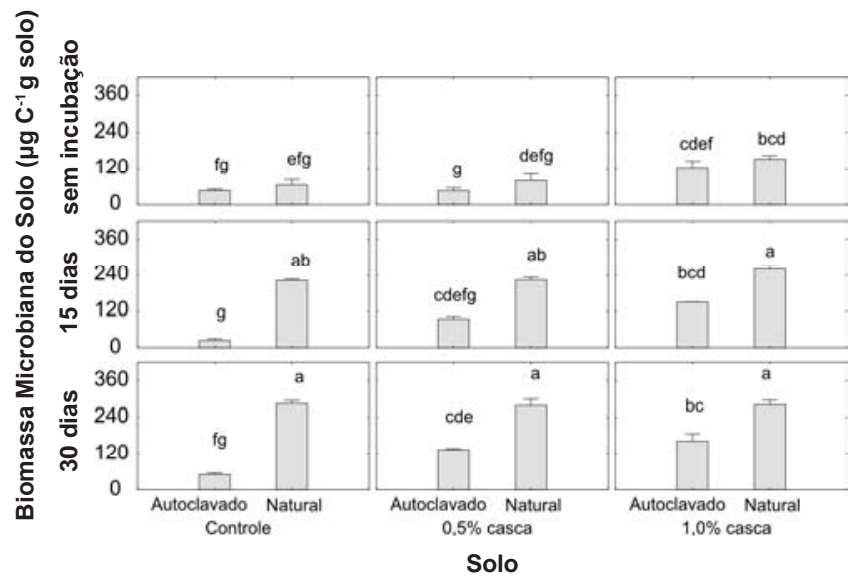

FIG. 1 - Biomassa microbiana de solos autoclavado e natural, adicionados de casca de caranguejo (Ucides cordatus), sem incubação ou incubada por 15 e 30 dias, e cultivado com plantas de pimenta-do-reino (Piper nigrum), por 90 dias. Os valores são médias (+ erro padrão). Letras diferentes sobre as colunas indicam diferença significativa (Tukey a 5\%).

Incrementos significativos na massa seca das plantas foram obtidos com a adição de $0,5 \%$ de casca de caranguejo, nos solos estudados (Figura 2). Melhor resposta foi obtida quando a casca de caranguejo foi adicionada na concentração de $0,5 \%$, principalmente quando foi pré-incubada no solo por 15 dias. Apesar de não ter sido possível detectar diferença significativa entre tratamentos quando a casca de caranguejo foi adicionada no ato do transplantio, sem pré-incubação, ou após 30 dias de pré-incubação, a mesma tendência foi observada. É possível especular que o aumento na disponibilidade de $\mathrm{N}$ (entre outros nutrientes) no solo contribuiu para a obtenção desses resultados, considerando que a quantidade desse macronutriente contida em $0,5 \%$ de casca de caranguejo foi de $53 \mathrm{mg} \mathrm{kg}^{-1}$ de solo. Esse resultado é compatível com aqueles obtidos em pesquisas com plantas jovens de pimenteira-do-reino, onde foi demonstrado que a dose ótima estimada de $\mathrm{N}$ para a produção de massa seca da parte aérea, utilizando uréia como fonte de $\mathrm{N}$, foi de $58 \mathrm{mg}$ $\mathrm{kg}^{-1}$, e que essa produção decresceu, à medida que a dose
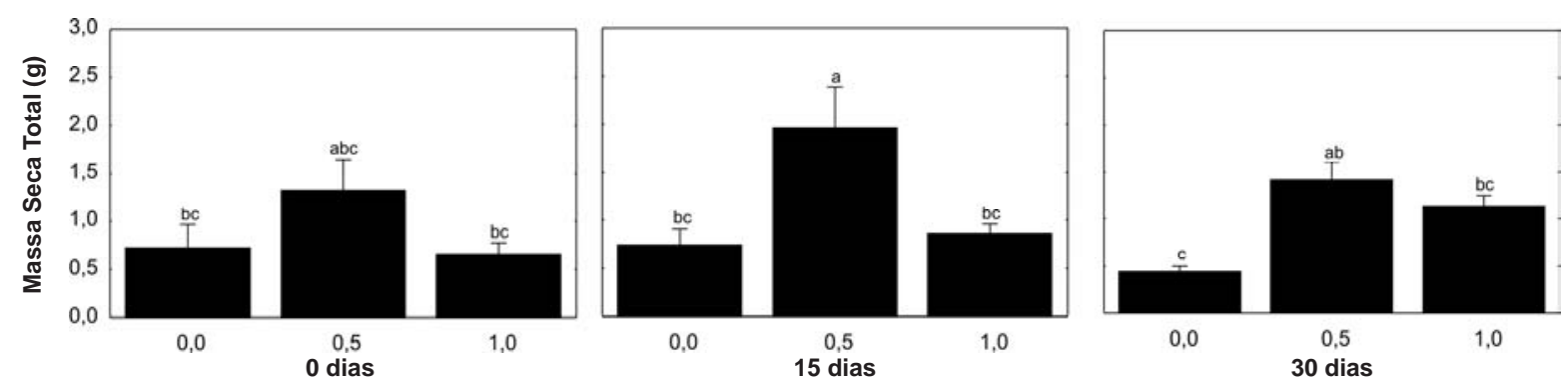

FIG. 2 - Massa seca total de plântulas de pimenteira-do-reino (Piper nigrum) cultivadas por 150 dias em solo de mata autoclavado adicionado de 0,5 ou 1,0 \% de casca de caranguejo (Ucides cordatus), sem pré-incubação ou pré-incubada por 15 ou 30 dias antes do transplantio. Os valores são médias (+ erro padrão). Letras diferentes sobre as colunas indicam diferenças significativas (Tukey a 5\%). 
aumentou [dados não publicados; Oliveira, R.F. (2005), informação pessoal], o que também foi observado quando a dose de 1,0\% (106 mg kg-1 de solo) foi aplicada ao solo. Ainda, o aumento na disponibilidade de $\mathrm{N}$ e outros nutrientes no solo pode também ter induzido à maior alocação de biomassa para a parte aérea, principalmente para as folhas, como resposta a menor necessidade de produção de raízes para a absorção de nutrientes (Fitchner, 1995), conforme observado na Figura 3, considerando-se folhas, haste e raiz, isoladamente.

A adição de casca de caranguejo tendeu a aumentar a taxa fotossintética líquida das plantas (Figura 4). No entanto, observou-se tendência de menores taxas fotossintéticas nas plantas cultivadas em solo natural e onde a casca de
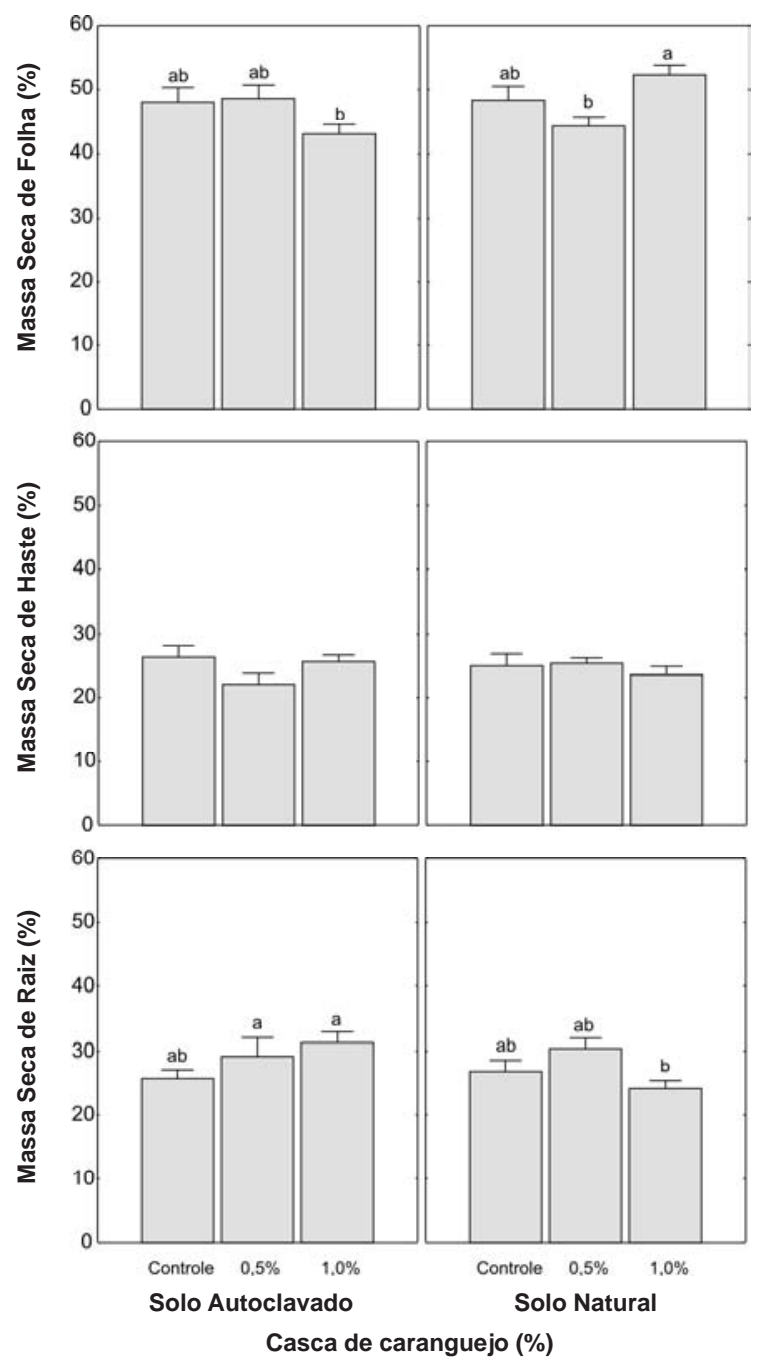

FIG. 3 - Alocação de biomassa em plantas de pimenteira-doreino (Piper nigrum), cultivadas por 150 dias em solo de mata autoclavadodicionado de casca de caranguejo (Ucides cordatus), independente do tempo de pré-incubação. Os valores são médias (+ erro padrão). Letras diferentes sobre as colunas indicam diferença significativa $(\mathrm{p}<0,05)$ entre tratamentos, para cada variável (Teste de Tukey). Não foi detectada diferença significativa entre tratamentos para a variável massa seca da haste.

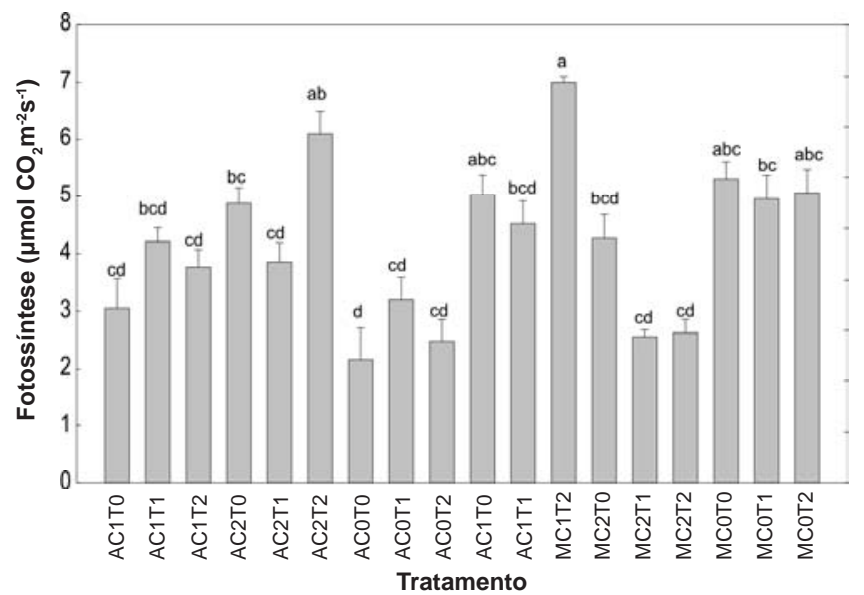

FIG. 4 - Fotossíntese líquida em mudas de pimenteira-doreino (Piper nigrum), cultivadas por 150 dias em solo de mata autoclavado, adicionado de diferentes concentrações de casca de caranguejo (Ucides cordatus) e tempos de pré-incubação. Os valores são médias (+ erro padrão). A= solo de mata autoclavado; $\mathrm{M}=$ solo de mata natural; $\mathrm{C} 0=$ sem casca; $\mathrm{C} 1=0,5 \% ; \mathrm{C} 2=1,0 \%$; $\mathrm{T} 0=$ sem pré-incubação; $\mathrm{T} 1=15$ dias de pré-incubação; $\mathrm{T} 2=30$ dias de pré-incubação. Letras diferentes sobre as colunas indicam diferença significativa (Tukey a 5\%).

caranguejo foi incubada na concentração de 1,0\%, não tendo sido detectada, porém, diferença significativa entre esses valores e os do tratamento testemunha.

Com base nos resultados obtidos, conclui-se que a casca de caranguejo auxilia na redução da incidência de fusariose e na promoção do crescimento de mudas de pimenteira-do-reino.

\section{AGRADECIMENTOS}

Os autores agradecem aos revisores, em especial ao Dr. Wagner Bettiol, pela significativa contribuição dada para a melhoria deste manuscrito.

\section{REFERÊNCIAS BIBLIOGRÁFICAS}

ADACHI, K., KOBAYASHI, M. \& TAKAHASHI, E. Effect of application of lignin and/or chitin to soil inoculated with Fusarium oxysporum on the variation of soil microflora and plant growth. Soil Science and Plant Nutrition 33:245-260. 1987.

ALBUQUERQUE, F.C. Podridão das raízes e do pé da pimentado-reino. Belém, IPEAN, 1961. 45p. (IPEAN, Circular 5).

ALI, M., TAKATSUGU, H. \& MIYAGAWA, S. Effects of soil amendment with crab shell on the growth and nodulation of soybean plants (Glycine max Merr.). Plant Production Science 1:119-125. 1998.

BAKER, R. \& PAULITZ, T.C. Theoretical basis for microbial interactions leading to biological control of soilborne plant pathogens. In: Hall, R. (Ed.) Principles and Practice of Managing Soil borne Plant Pathogens. Saint Paul MN. APS Press. 1996. pp. 51-79. 
BENCHIMOL, R.L. Efeito da casca de caranguejo e de resíduos de Piper aduncum no controle da fusariose e no desenvolvimento de mudas de pimenteira-do-reino. (Tese de Doutorado). Belém PA. Universidade Federal do Pará. 2002.

BETTIOL, W. \& GHINI, R. Métodos alternativos usados com sucesso no Brasil para o controle de doenças de plantas. In: Stadnick, M.J. \& Talamini, V. (Eds.) Manejo Ecológico de Doenças de Plantas. Florianópolis SC. CCA/UFSC. 2004. pp. 143-157.

BOLLER, T. Chitinase: A defense of higher plants against pathogens. In: Muzzarelli, R., Jeuniaux, C. \& Gooday, G.W., (Eds.) Chitin in nature and Technology. New York. Plenum Press. 1986. pp. 223-230.

BROWN, J.A., NEVILLE, F.J., SARATHCHANDRA, S.U., WATSON, R.N. \& COX, N.R. Effect of chitin amendment on plant growth, microbial populations and nematodes in soil. Proceedings, 48th New Zealand Plant Protection Conference. Hamilton New Zealand. 1995. pp. 208-212.

CENDETECA Informe técnico. Santo Domingo, República Dominicana, 1995. pp. 110-130.

DUARTE, M.L.R. \& ALBUQUERQUE, F.C. Impacto das doenças de plantas na economia da Amazônia. In: Duarte, M.L.R. (Ed.) Doenças de Plantas do Trópico Úmido Brasileiro. I. Plantas Industriais. Belém PA. Embrapa Amazônia Oriental. 1999. pp. 1524.

EHTESHAMUL-HAQUE, S., SULTANA, V., ARA, J., QASIN, R. \& GHAFFAR, A. Use of crustacean chitin and plant growth promoting bacteria for the control of Meloidogyne javanica root knot nematode in chickpea. Pakistan Journal of Nematology 15:8993. 1997.

FICHTNER, K. \& SCHULZE, E.D. The effect of nitrogen nutrition on growth and biomass partitioning of annual plants originating from habitats of different nitrogen availability. Oecologia 92:236241. 1992.

GAGNON, B. \& BERROUARD, S. Effects of several organic fertilizers on growth of greenhouse tomato transplants. Canadian Journal of Plant Science 74:167-168. 1994.

GODOY, G., RODRIGUEZ-KABANA, R., SHELBY, R.A. \& MORGAN-JONES, G. Chitin amendments for control of Meloydogine arenaria in infested soils. 2. Effects of microbial populations. Nematropica 13:63-74. 1983.

GRIFFIN, D.H. Fungal physiology. New York. Wiley Inc. 1993.

HALLMANN, J., RODRÍGUEZ-KÁBANA, R. \& KLOEPPER, J.W. Chitin-mediated changes in bacterial communities of the soil, rhizosphere and within roots of cotton in relation to nematode control. Soil Biology and Biochemistry 31:551-560. 1999.

HUANG, J.W. \& HUANG, H.C. A formulated container medium suppressive to Rhizoctonia damping-off of cabbage. Botanical Bulletin of Academia Sinica 41:49-56. 2000.

KAHN, B.A., DAMICONE, J.P., JACKSON, K.E., MOTES, J.E. \& PAYTON, M.E. Comparing chitin-urea to other materials for control of northern root-knot nematode on paprika pepper.
Hortscience 37:948-949. 2002.

LIN, Y.S., SUN, S.K., HSU, S.T. \& HSIEH, W.H. Mechanisms involved in the control of soil-borne plant pathogens by S-H mixture. In: Hornby, D. (Ed.) Biological Control of Soil-borne Plant Pathogens. Wallingford UK. CAB International. 1990. pp. 249-259.

MIAN, I.H., GODOY, G., SHELBY, R.A., RODRÍGUEZKÁBANA, R. \& MORGAN-JONES, G. Chitin amendments for control of Meloidogyne arenaria in infested soil. Nematropica. 12:71-84. 1982.

MITCHELL, R. \& ALEXANDER, M. Chitin and the biological control of Fusarium diseases. Plant Disease Reporter 45:487-490. 1961.

MITCHELL, R. \& ALEXANDER, M. Microbiological processes associated with the use of chitin for biological control. Soil Science Society of America Proceedings 26:556-558. 1962.

PARÁ. Embrapa Amazônia Oriental. Sistema de Produção. Belém, 2004. Disponível em: http//www.cpatu.embrapa.br/pimenta/ pimentadoreino.htm. acesso em 15.fev.2005.

RAFFERTY, S.M., MURPHY, J.G. \& CASSELLS, A.C. Lytic enzyme activity in peat is increased by substrate amendment with chitin: Implications for the control of Phytophthora fragariae in Fragaria vesca. Folia-Geobotanica 38:139-144. 2003.

RODRIGUÉZ-KÁBANA, R., GODOY, R., MORGAN-JONES, G. \& SHELBY, R.A. The determination of soil chitinase activity. Conditions of assay and ecological study. Plant Soil 75:95-106. 1983.

SARATHCHANDRA, S.U., WATSON, R.N., COX, N.R., MENNA, M.E.; BROWN, J.A., BURCH, G. \& NEVILLE, F.J. Effects of chitin amendment of soil on microorganisms, nematodes and growth of white clover (Trifolium repens L.) and perennial ryegrass (Lollium perenne L.). Biology and Fertility of Soils 22:221-223. 1996.

SNEH, B., KATAN, J. \& HENIS, Y. Mode of inhibition of Rhizoctonia solani in chitin-amended soil. Phytopathology 61:1113-1117. 1971.

STATISTICA for Windows. General conventions and statistics. v.1. Tulsa, StatSoft, Inc. 1995.

TATE, K.R., ROSS, D.J. \& FELTHAM, C.W. A direct extraction method to estimate soil microbial C: Effects of experimental variables and some different calibration procedures. Soil Biology and Biochemistry 20:329-335. 1988.

TU, C.C., HSIEH, T.F. \& TSAI, W.H. Studies on control of lily southern blight by application of soil amendments. Journal of Agricultural Research of China 41:280-294. 1992.

TUITE, J. Plant pathological methods; fungi and bacteria. Minneapolis. Burgess Publishing Company. 1969.

VANCE, E.D., BROOKES, P.C. \&, JENKINSON, D.S. An extraction method for measuring soil microbial biomass C. Soil Biology and Biochemistry 19:703-707. 1987. 